\title{
The health workforce crisis in TB control: a report from high-burden countries José Figueroa-Munoz*1, Karen Palmer ${ }^{1}$, Mario R Dal Poz², Leopold Blanc, Karin Bergström ${ }^{1}$ and Mario Raviglione ${ }^{1}$
}

\author{
Address: ${ }^{1}$ Tuberculosis Strategy and Operations, Stop TB Department, World Health Organization, Geneva, Switzerland and ${ }^{2}$ Department of \\ Human Resources for Health, World Health Organization, Geneva, Switzerland \\ Email: José Figueroa-Munoz* - figueroamunozj@who.int; Karen Palmer - kpalmer@mtwest.net; Mario R Dal Poz - dalpozm@who.int; \\ Leopold Blanc - blancl@who.int; Karin Bergström - bergstromk@who.int; Mario Raviglione - raviglionem@who.int \\ * Corresponding author
}

Published: 24 February 2005

Human Resources for Health 2005, 3:2 doi:10.1186/1478-449I-3-2
Received: 3I August 2004

Accepted: 24 February 2005

This article is available from: http://www.human-resources-health.com/content/3/I/2

(C) 2005 Figueroa-Munoz et al; licensee BioMed Central Ltd.

This is an Open Access article distributed under the terms of the Creative Commons Attribution License (http://creativecommons.org/licenses/by/2.0), which permits unrestricted use, distribution, and reproduction in any medium, provided the original work is properly cited.

\begin{abstract}
Background: Human resources (HR) constraints have been reported as one of the main barriers to achieving the 2005 global tuberculosis (TB) control targets in 18 of the 22 TB high-burden countries (HBCs); consequently we try to assess the current HR available for TB control in HBCs.

Methods: A standard questionnaire designed to collect information on staff numbers, skills, training activities and current staff shortages at different health service levels was sent to national TB control programme managers in all HBCs.

Results: Nineteen HBCs (86\%) replied, and 17 (77\%) followed the questionnaire format to provide data. Complete information on staff numbers at all service levels was available from nine countries and data on skill levels and training were complete in six countries. Data showed considerable variations in staff numbers, proportions of trained staff, length of courses and quality of training activities. Eleven HBCs had developed training materials, many used implementation guidelines for training and only three used participatory educational methods. Two countries reported shortages of staff at district health facility level, whereas I 4 reported shortages at central level. There was no apparent association between reported staff numbers (and skills) and the country's TB burden or current case detection rates (CDR).

Conclusion: There were few readily available data on HR for TB control in HBCs, particularly in the larger ones. The great variations in staff numbers and the poor association between information on workforce, proportion of trained staff, and length and quality of courses suggested a lack of valid information and/or poor data reliability. There is urgent need to support HBCs to develop a comprehensive HR strategy involving short-term and long-term HR development plans and strengthening their HR planning and management capabilities.
\end{abstract}

\section{Background}

The performance of health care systems is closely related to the numbers, distribution, knowledge, skills and moti- vation of its workforce, particularly of those individuals delivering the services [1]. Improvements in global health are greatly dependent on how well health systems can 
meet the demands placed on them by governments, programmes, communities and ultimately individuals. Human resources for health (HRH), all categories of clinical and non-clinical staff who make each individual and public health intervention happen, constitute a sine qua non of health systems. Therefore, developing HRH and fostering appropriate HR management are crucial steps towards achieving and sustaining improved and equitable health.

Tuberculosis (TB) constitutes the third most important cause of death and disability [2] among infectious diseases. It is estimated that in 2002, there were 8.8 million new TB cases worldwide (141/100 000) of which 3.9 million were sputum-smear positive (SS+). Despite control efforts, the global incidence of TB continues to grow in some regions, particularly in sub-Saharan Africa [3]. The emergence of AIDS and multidrug-resistant TB (MDR-TB) pose further challenges for global TB control; in 2000 there were 1.82 million TB-related deaths, of which 226 $000(12 \%)$ were attributable to $\operatorname{HIV}[2,4]$.

The World Health Assembly (WHA), in 1991, pledged countries to achieve detection of at least $70 \%$ of estimated infectious TB cases (SS+) and to cure $85 \%$ of them by the year 2000 [5]. Slow progress resulted in the deferral of these targets until 2005 [6]. Likewise, the United Nations commitment to sustaining development and eliminating poverty throughout the world led world leaders to formulate the eight Millennium Development Goals (MDGs), among them to halt, and begin to reverse, the global incidence of TB by 2015 [7]. The creation of the Stop TB Partnership in 1998 [8] and the Global Fund to fight AIDS, TB and Malaria (GFATM) in 2001 [9] represented significant developments in the fight against TB, thanks to increased financing and technical assistance made available to endemic countries. However, disease-specific programmes (including TB) are still struggling to meet their targets, and governments and their financial/technical partners have finally recognized this is largely due to shortcomings in the health care workforce $[3,10]$.

Low-income and middle-income countries (LMIC) urgently need a sufficiently large health care staff with appropriate expertise, experience and motivation, working at the right places. Lack of HR strategies, inadequate HR planning and management, poor deployment practices, inflexible contracting arrangements and inability to create new posts or increase salaries resulting from international regulations capping social sector spending have contributed to the global HRH crisis [10]. In addition, poor salaries, low morale and worsening local economic circumstances result in low recruitment/retention, internal and external migration of trained staff and attrition of the health care workforce. The HIV/AIDS epidemic has increased pressure on health systems and causes death and disability of the workforce itself [11].

In 2003, national TB programme (NTP) managers from 18 of the 22 TB high-burden countries (HBCs, countries that together account for approximately $80 \%$ of the global TB burden), ranked inadequate HR first within the top five constraints to reaching the WHA global TB control targets [3]. Insufficient numbers, lack of adequately qualified or trained staff at different service levels, inadequate distribution, low motivation and poor staff retention were commonly described. Although some components of disease control programmes still remain vertical (e.g. drug procurement or laboratory QA) the majority of front-line services are now partially or totally integrated to primary health care and therefore a shortage of HR for TB control represents a shortage of HR for health delivery.

There is very limited published literature on HRH issues, particularly in LMIC and there are both scanty information on methods to assess HR capacity and lack of evidence on how best to evaluate interventions to strengthen and/or build HR capacity [12]. The dearth of published information probably stems from the persistent neglect of $\mathrm{HRH}$ development issues; in addition, research in $\mathrm{HRH}$ involves a broad scope of disciplines and often different research methodologies than those recognized in clinical medicine [13].

Currently there is increasing awareness that HRH concerns must be addressed in order to reach the MDGs, to expand access to priority interventions, to promote health systems development and to achieve global health equity $[14,15]$. However, without reasonably accurate information on numbers, location, qualifications and activities of staff, it is not possible to effectively manage or plan HR for the country's health services or for specific programmes [16].

This paper reports the results of a questionnaire sent to NTP staff in the 22 HBCs to assess the workforce available for TB control (staff numbers, cadres and skills), as well as the estimated HR requirements for appropriate TB control in HBCs. It aims to inform the development of more reliable methods of gathering qualitative and quantitative information on HR and to stimulate a long-overdue discussion on HR for TB control issues, so that governments of endemic countries and technical and financial partners can finally begin to address them jointly.

\section{Methods \\ Participants}

NTP managers and country-based WHO staff in the 22 HBCs: Afghanistan, Bangladesh, Brazil, Cambodia, China, Democratic Republic of the Congo, Ethiopia, 
India, Indonesia, Kenya, Mozambique, Myanmar, Nigeria, Pakistan, Philippines, the Russian Federation, South Africa, Tanzania, Thailand, Uganda, Viet Nam and Zimbabwe. These countries account for more than half of the world's population and approximately $80 \%$ of the global TB burden

\section{Questionnaire}

Discussions with NTP managers and a literature review on $\mathrm{HRH}$ informed the development of a questionnaire to ascertain current staff provision; quality and intensity of training; time and type of personnel involved in performing different TB control activities; and estimated staffing needs at different health service levels. The questionnaire was pilot-tested internally within the Stop TB Department (STB), WHO headquarters, Geneva; and externally with staff from the NTP in Indonesia.

The first section of the questionnaire assessed staff numbers and skills. It included open questions about absolute numbers of staff involved in delivering TB control activities at each service level (provincial, district and health facility and laboratory personnel). Skills were assessed using a composite of the proportion of staff receiving training in the previous three years (at each level) and the quality of the training provided (length of courses, development of educational materials and/or use of standard WHO or International Union Against Tuberculosis and Lung Diseases (IUATLD) - materials) as proxy measures.

Section two of the questionnaire addressed estimated HR gap. Since this paper specifically refers to TB control, we estimated the workload involved in adequate TB control in HBCs. Workloads were assessed by means of open questions on the different processes involved in the management of new SS+ patients (diagnosis and administration of a short course chemotherapy regimen under proper case management conditions including directly observed therapy, DOT), the estimated duration of each task and the type of staff involved in delivering them. A series of worksheets containing the different tasks required for $\mathrm{TB}$ case management were designed to assist respondents completing the questionnaire and to improve standardization. Capacity of health services at two different CDRs were assessed (current CDR and at the target 70\% CDR). Workloads at current CDRs were calculated by multiplying the current numbers of new SS+ patients by the estimated time needed to treat a new SS+ patient; workloads at the 70\% CDR were calculated by multiplying the figure corresponding to $70 \%$ of the estimated SS+ TB cases for each country by the time needed to treat a new SS+ patient. Eleven hours was used as the time needed to treat a new SS+ patient; this had been estimated previously by a TB experts' consensus (WHO, unpublished data).

\section{Survey}

In March 2003, the questionnaire, together with detailed instructions in English, was e-mailed to NTP managers and country-based WHO staff in the 22 HBCs. Three email reminders were sent monthly after the return deadline; follow-up with several countries included e-mail and telephone communications to clarify responses. Data were entered into spreadsheet software for the analysis; qualitative answers were discussed by the authors.

\section{Results \\ Response rate}

Nineteen of the 22 HBCs returned the questionnaire ( $86 \%$ response rate). Two countries provided information on their HR for TB control but did not use the questionnaire format and were thus excluded from the analysis; one country reported that it would take a substantial amount of time to get reliable information from such a large country and provided other readily available HR information; another reported that given the country's current staffing deficits and competing priorities they were unable to complete the survey. Further discussions revealed that some HR information was available in this country, although it was scattered in different sources and lengthy to compile. Both countries requested technical support to assess staffing needs at different levels and to assist their government's HR development programmes. Despite e-mail and telephone remainders, three countries failed to respond.

\section{Numbers of staff}

Information on estimated numbers of staff was available from all 17 countries but complete in nine (53\%) of them. Staff numbers within the same service level varied considerably between countries; i.e. numbers of staff at provincial level varied from 8704 in one country to 6 staff in two countries (Table 1); similar variations were seen at other service levels. More countries provided information on staff numbers at provincial than at district or health facility levels.; only nine countries (53\%) provided numbers of staff at laboratory level.

\section{Skills}

Complete information on numbers of staff trained in the previous three years was available in only six countries (35\%). There was also great variation in the numbers (or proportions) of trained staff (Table 1). Indonesia reported it trained $100 \%$ of staff at all levels, but this was based on its target for 2002; Viet Nam reported high levels of training at health facility and laboratory levels and South Africa reported high levels of training (70\% to $80 \%)$ at provincial, district and health facility levels (although absolute numbers were missing). Other countries either reported very low levels of training or had missing 
Table I: Staff numbers at each level and estimated numbers of trained staff in the previous three years (2000-2002)

\begin{tabular}{|c|c|c|c|c|c|c|c|c|}
\hline \multirow[t]{3}{*}{ Country } & \multicolumn{8}{|c|}{ Health service Level } \\
\hline & \multicolumn{2}{|c|}{ Provincial } & \multicolumn{2}{|c|}{ District } & \multicolumn{2}{|c|}{ Health facility } & \multicolumn{2}{|c|}{ Laboratory } \\
\hline & Total & Trained (\%) & Total & Trained (\%) & Total & Trained (\%) & Total & Trained (\%) \\
\hline Afghanistan & 40 & $22(55)$ & 360 & - & - & - & - & $30(--)$ \\
\hline Bangladesh & 460 & $150(33)$ & 460 & $120(26)$ & 39329 & $750(2)$ & 1015 & $450(44)$ \\
\hline Brazil & 27 & $19(70)$ & - & $20(--)$ & - & 6379 (--) & - & - \\
\hline Cambodia & - & $72(--)$ & - & $236(--)$ & 1120 & $705(63)$ & - & - \\
\hline DR Congo & 56 & $19(34)$ & 306 & - & 4306 & - & 1000 & - \\
\hline Ethiopia & 12 & $4(33)$ & - & - & - & - & - & - \\
\hline Indonesia* & 70 & $70(100)$ & 420 & $420(100)$ & 1256 & $1256(100)$ & 405 & $405(100)$ \\
\hline Kenya & $10 \pi$ & $7(70)$ & 94 & - & 45900 & $1 \mid 48(2)$ & 2121 & $350(16)$ \\
\hline Myanmar & - & $8(--)$ & - & $276(--)$ & - & $18056(--)$ & - & $327(--)$ \\
\hline Nigeria & 37 & $19(5 \mathrm{I})$ & 664 & $149(22)$ & 27000 & $295(I)$ & 3000 & $160(5)$ \\
\hline Pakistan & 6 & $0(0)$ & 60 & $60(100)$ & 21000 & $500(2)$ & 600 & $200(33)$ \\
\hline Philippines & 156 & - & 748 & - & 13900 & - & 2200 & - \\
\hline Russian Fed.§ & - & - & - & 4062 (--) & - & 4197 (--) & - & 1167 (--) \\
\hline South Africa & 9 & $9(100)$ & - & $(70-80)$ & 202265 & $(70-80)$ & - & - \\
\hline UR Tanzania & 25 & $2(8)$ & 156 & $58(37)$ & - & $50(--)$ & - & - \\
\hline Uganda & 6 & $3(50)$ & 55 & - & 1050 & - & 350 & - \\
\hline Viet Nam & 8704 & $2205(25)$ & 2705 & I $248(46)$ & 10510 & $10510(100)$ & 804 & $624(77)$ \\
\hline
\end{tabular}

* Percentage of training according to 2002 training plan

TAt regional level

$\S$ Federation

information. Only six countries (35\%) reported accurate information on training of laboratory staff.

Information on length of training courses and development of training materials was also incomplete. Length of courses for staff at the same service level varied greatly between countries; for example, courses for TB coordinators at provincial level (data from 11 countries) varied from 4 to up to 60 days, whereas at district level (information from 10 countries) courses varied from 4 days to 4 months (Table 2). Similar variations were reported at other levels. Development of training materials was reported by eight $(47 \%)$; a further four $(23 \%)$ reported developing lectures and exercises modules for training at all levels, whereas only three (18\%) described using participatory educational methods. Nine countries (53\%) had not developed specific training modules; five of them used WHO/IUATLD materials and the remaining countries used programme implementation manuals and guidelines as training tools. Altogether eight countries (47\%) reported using WHO/IUATLD training materials. The WHO/STB training modules for health facility staff take normally five days to complete if all its tasks and units are included; only one of the countries that reported using it had a five-day course. Training at this level took three days or less in six of the 12 countries with available information.

\section{Performance}

The estimated time needed to treat a new SS+ patient is shown in Figure 1. Times were positively skewed and ranged from 5 to 36 (mode 10) hours. Eight countries (47\%) needed from 9 to 12 hours; Brazil was the only country requiring less than 9 hours; Pakistan, Uganda, Nigeria, Kenya, Russia and Philippines were out-layers requiring between 22 to 36 hours. The Russian Federation ( 31 hours) and the Philippines (36 hours) took the longest, due to the policy to hospitalize all patients during the intensive phase of treatment in the former and the tendency to perform strict DOT during the continuation phase in the latter.

\section{Estimated HR gap}

Sixteen countries (Table 3) reported information on estimated shortages of staff at peripheral level (health facility) at current or target CDRs. Two countries $(12 \%)$ reported shortages of staff at current CDR, whereas five countries (29\%) predicted health facility staff shortages at the $70 \%$ CDR. Estimated numbers of staff needed varied from 1009 more nurses in Afghanistan to 8981 health care workers in Myanmar; Uganda reported shortages of staff but did not estimate the numbers needed. Eleven countries $(65 \%)$ reported no shortages of health facility staff at current or at $70 \%$ CDRs; these included countries with low current CDR and no data on staff numbers. 
Table 2: Length of training courses at different training levels and development of training materials by country

\begin{tabular}{|c|c|c|c|c|c|}
\hline \multirow[t]{3}{*}{ Country } & \multicolumn{4}{|c|}{ Length of training in days } & \multirow{3}{*}{ Training materials* } \\
\hline & \multicolumn{2}{|c|}{ TB coordinator } & \multirow{2}{*}{$\begin{array}{l}\text { Staff health facility } \\
\text { level }\end{array}$} & \multirow{2}{*}{$\begin{array}{l}\text { Laboratory } \\
\text { staff }\end{array}$} & \\
\hline & Provincial level & District level & & & \\
\hline Afghanistan & 10 & - & - & 7 & No materials developed \\
\hline Bangladesh & - & $4-6$ & $2-3$ & 6 & $\begin{array}{l}\text { Developed lectures and exercises, also uses WHO } \\
\text { materials for training at provincial and district levels }\end{array}$ \\
\hline Brazil & 5 & 5 & 5 & 5 & Developed manuals \& guidelines for all levels \\
\hline Cambodia & - & 5 & 3 & - & Developed training modules at all levels \\
\hline DR Congo & 21 & - & - & - & $\begin{array}{l}\text { No materials developed, uses WHO materials at all } \\
\text { levels }\end{array}$ \\
\hline Ethiopia & - & $7-10$ & 5 & 5 & Ad hoc handouts \\
\hline Indonesia & 12 & 12 & 6 & 8 & Developed training modules for all levels \\
\hline Kenya & 15 & - & 2 & 3 & $\begin{array}{l}\text { No specific training materials developed, uses } \\
\text { national guidelines and WHO \& IUATLD training } \\
\text { materials }\end{array}$ \\
\hline Myanmar & 5 & 5 & 1 & 5 & $\begin{array}{l}\text { TB manual for health facility staff and lab. } \\
\text { technicians developed in } 2002\end{array}$ \\
\hline Nigeria & 21 & 120 & 3 & 6 & $\begin{array}{l}\text { Developed training materials at all levels, did not } \\
\text { specify }\end{array}$ \\
\hline Pakistan & - & 10 & variable $\S$ & 10 & $\begin{array}{l}\text { Developed training modules, translated WHO } \\
\text { materials for training lab. staff }\end{array}$ \\
\hline Philippines & - & - & - & - & Use modified WHO materials at all levels \\
\hline Russian Fed. & - & - & - & - & $\begin{array}{l}\text { WHO materials were developed for Russia in } \\
2002 \text {, use manuals and guidelines for staff at } \\
\text { different levels }\end{array}$ \\
\hline South Africa & 4 & - & 3 & - & $\begin{array}{l}\text { No specific materials developed, uses WHO \& } \\
\text { IUATLD materials for different levels }\end{array}$ \\
\hline UR Tanzania & 14 & 30 & 5 & 5 & $\begin{array}{l}\text { Developed a TB Manual but no specific training } \\
\text { materials }\end{array}$ \\
\hline Uganda & 15 & - & - & - & Developed training materials but did not specify \\
\hline Viet Nam & 10 or 60 & 5 or 10 & 3 or 5 & $15-20$ & $\begin{array}{l}\text { Uses national guidelines for training, for health } \\
\text { facility staff it uses WHO \& IUATLD training } \\
\text { materials }\end{array}$ \\
\hline
\end{tabular}

* Development of specific training materials for each country or use of standard WHO / IUATLD modules and courses.

$\S$ Variable: Medical staff 6 days, paramedical 3 days, health workers I day.

All countries provided information on their estimated HR gap at district level; nine (53\%) countries reported existing staff needs at district level (Table 3); nine countries reported existing needs at provincial level and all but two countries reported staff needs at central level. Some countries answered qualitatively while others estimated numbers needed, but it is not clear how these estimates were reached. Cambodia and Viet Nam were the only HBCs reporting no staff shortages at any service level. Afghanistan, Cambodia, Ethiopia, Kenya and Uganda reported poor distribution of staff. Brazil, Cambodia, Democratic Republic of the Congo, Ethiopia, Nigeria and Viet Nam reported training and capacity-building shortfalls.

\section{Discussion}

In many HBCs, NTP managers do not have access to accurate information on numbers, types and distribution of staff involved in TB control activities. As previously stated, TB control programmes are partially or fully integrated into health care systems; this lack of HR information thus could at best indicate poor communication and coordination between NTP managers and HR planners or, at worst, a general lack of information on HR in the health care system. In order to adequately manage and plan HR it is important to have up-to-date information on the quantity, distribution and skills of the existing health care workforce [16]. It is therefore imperative to assist HBCs to develop and maintain appropriate HR databases so that the necessary information for planning and managing their health care workforce can be readily accessible.

Accreditation is often used as a proxy for competence for professional groups (doctors and nurses); for other health care staff, adequate competence is ensured through regu- 


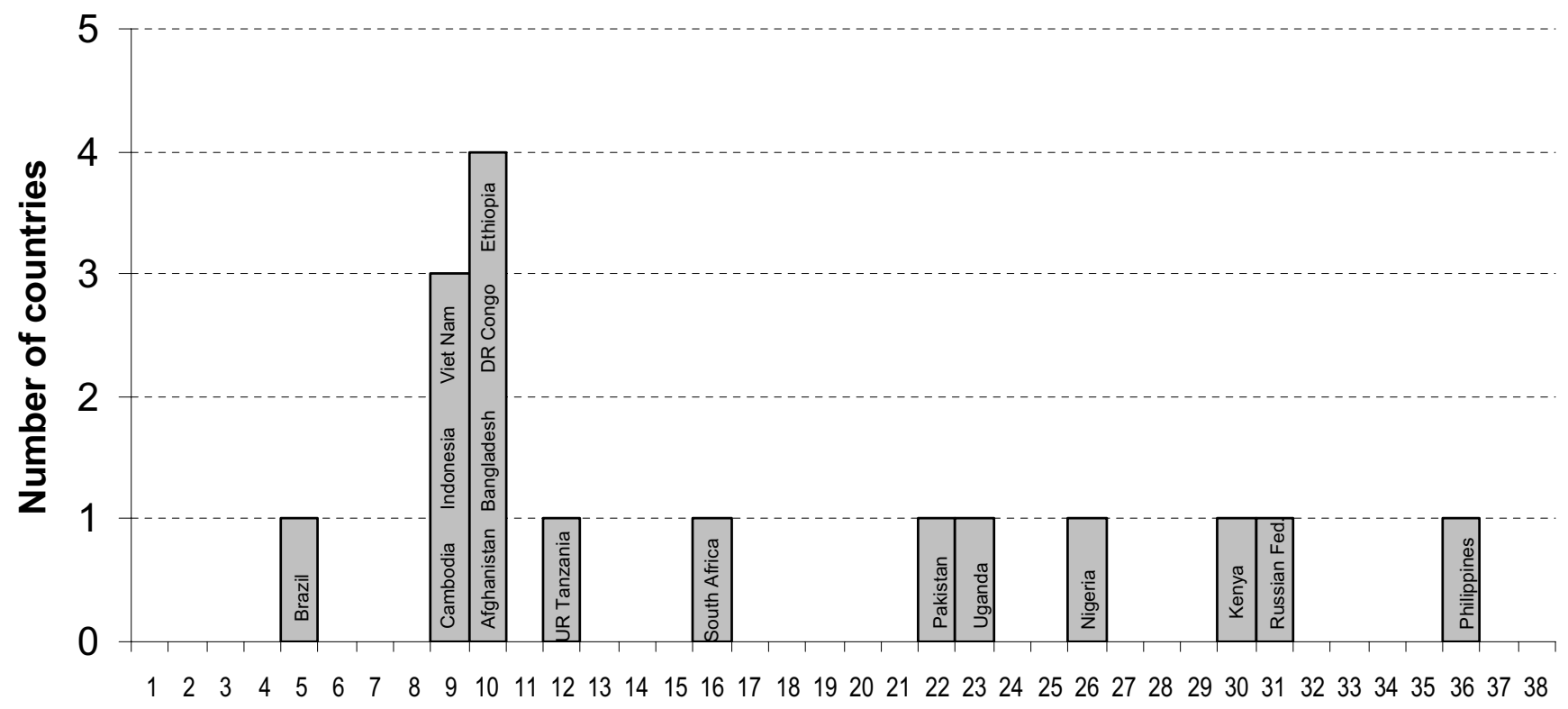

Average time in hours

\section{Figure I}

Average time spent to treat one new sputum-smear positive TB patient

lar training and supervision. Apart from Indonesia and Viet Nam, there was no correlation between information on numbers of staff, attendance of training courses, length of courses and development of training materials. In general NTP managers in HBCs had limited information on staff attendance of training courses and on the characteristics, duration and intensity of training activities. HBCs need to develop needs-based comprehensive training policies and training strategies for health care staff at all service levels, incorporating pre-service training, re-training, in-service support and continuous professional/career development. Similarly, it is important to emphasize the role of periodic monitoring and supervisory visits as part of the staff continuous education and support processes. Appropriately designed strategies fostering career paths could increase staff motivation and performance; improve staff recruitment, retention and distribution; and even have a positive effect on enlisting of students into training programmes [17] and expansion of the health care workforce.

The quality of training materials was also of concern: many countries used inadequate training tools, few had developed specific modules and even fewer used problem-based learning or participatory methodology to facilitate adequate skill development. The length of courses also varied greatly: while very short courses do not allow the development of skills and competences needed to improve performance, lengthy courses have economic and logistic implications. Differences in the quality and intensity of training could translate into service or performance variations with detrimental effects to programmes and ultimately to patients. There is a need to standardize training in terms of contents, competences, methodologies, course duration and quality of training materials. Improvement and standardization of training curricula and methodologies will facilitate the adoption of a universal standard of care for TB patients in HBCs, leading to a more rational use of the health care workforce, improved staff motivation and productivity and better outcomes for TB patients.

Although the majority of countries described deficiencies of staff at central level, few reported shortages in the actual numbers of posts. However, there were concerns about the distribution and/or the skill mix (competences and efficiency) of staff. There was no clear relation between reported data on staff needs and either the TB burden in the country or the actual performance of the NTP. It is of concern that only Uganda and Myanmar reported shortages of staff at current CDRs, whereas countries with very low current CDRs did not. Only five countries projected shortages of staff at the 70\% CDR; four of them estimated large numbers of staff required. 
Table 3: Perceived staff needs at different service levels. NTP managers were asked to report perceived staff needs at different service levels. Staff needs at Health Facility level were evaluated both at current and at the $\mathbf{7 0 \%}$ target case detection rates

\begin{tabular}{|c|c|c|c|c|c|c|c|}
\hline \multirow[t]{3}{*}{ Country } & \multirow[t]{3}{*}{ CDR* } & \multicolumn{5}{|c|}{ Perceived staff shortages } & \multirow[t]{3}{*}{ Comments } \\
\hline & & \multicolumn{2}{|c|}{ Health facility } & \multirow[t]{2}{*}{ District } & \multirow[t]{2}{*}{ Provincial } & \multirow[t]{2}{*}{ Central } & \\
\hline & & $\begin{array}{l}\text { At current } \\
\text { CDR }\end{array}$ & At $70 \%$ CDR & & & & \\
\hline Afghanistan & $19 \%{ }^{a}$ & No & 1009 & No & No & 17 & $\begin{array}{l}\text { Poor distribution of staff, staff } \\
\text { needed to run new facilities }\end{array}$ \\
\hline Bangladesh & $33 \%$ & No & No & No & No & $1-5$ & \\
\hline Brazil & $84 \%$ & No & No & Yes & & & $\begin{array}{l}\text { Capacity building of existing staff } \\
\text { is a priority }\end{array}$ \\
\hline Cambodia & $52 \%{ }^{a}$ & No & No & No & No & No & $\begin{array}{l}\text { Poor distribution and training of } \\
\text { staff at district and central levels }\end{array}$ \\
\hline DR Congo & $52 \%{ }^{a}$ & No & No & No & 52 & $>5$ & $\begin{array}{l}\text { Capacity building of existing staff } \\
\text { a priority }\end{array}$ \\
\hline Ethiopia & $33 \%{ }^{a}$ & & & Yes & 5 (regional) & 2 & $\begin{array}{l}\text { Lack of data, poor distribution } \\
\text { and training }\end{array}$ \\
\hline Indonesia & $30 \% \mathrm{a}$ & No & 3670 & Yes & Yes & Yes & \\
\hline Kenya & $49 \%^{\mathrm{a}}$ & No & No & No & No & 8 & Poor distribution of existing staff \\
\hline Myanmar & $73 \%^{a}$ & Yes & 8981 & 6 & 4 & 4 & \\
\hline Nigeria & $14 \%$ & No & No & No & 111 & 25 & $\begin{array}{l}\text { Capacity building of existing staff } \\
\text { is a priority }\end{array}$ \\
\hline Pakistan & $13 \%$ & No & 2981 & Yes & Yes & $>6$ & \\
\hline Philippines & $58 \% \mathrm{a}$ & No & No & $>3$ & Yes & $>10$ & \\
\hline Russian Fed.§ & $34 \%$ & No & No & No & No & Approx. 48 & Not enough data available \\
\hline South Africa & $97 \%$ & No & No & Yes & Yes & Yes & $\begin{array}{l}\text { Lack of funds for recruiting new } \\
\text { staff }\end{array}$ \\
\hline UR Tanzania & $43 \%{ }^{a}$ & No & No & $>364$ & $>88$ & $>11$ & $\begin{array}{l}\text { Staff retention and deployment } \\
\text { problems }\end{array}$ \\
\hline Uganda & $47 \%^{\mathrm{a}}$ & Yes & Yes & Yes (Zonal) & & 4 & Inconsistent data provided \\
\hline Viet Nam & $82 \%^{a}$ & No & No & No & No & No & $\begin{array}{l}\text { Poor training of existing staff at } \\
\text { district and provincial levels }\end{array}$ \\
\hline
\end{tabular}

* Case Detection Rate for 2002, Ref 3.

a No data available for the whole country; case detection rate for DOTS programmes

§Federation

If the assessment of the HR needs was based on the actual workload, it is possible no substantial gap was determined because most of the current diagnostic and treatment tasks are carried out satisfactorily by existing staff, but an unrecognized HR gap could hamper improvement in case detection rates. The inability of some countries to increase the number of posts because of recruitment ceilings imposed under structural adjustment programmes could lead to countries underreporting their HR gap. Further analysis and recommendations on staff needs at different levels is hindered by the lack of accurate information on numbers, quality and distribution of existing staff.

This survey is, to our knowledge, the first attempt to ascertain HR for TB control in HBCs. The response rate was high and responses were analysed in the context of the countries' estimated TB burden and current CDRs.

Limitations of the study are evidenced by the great variation in reported staff numbers and the lack of correlation between information on numbers of trained staff, length of courses, development of materials and performance, suggesting a shortage of valid information, poor standardization and/or data reliability.

The fact that the questionnaire was in English could have generated some inaccurate answers. Indonesia, for example, reported $100 \%$ training completion based on its 2002 training goals rather than in absolute numbers (the actual proportion of staff trained at health centre level was 35\%), but countries were re-contacted (by e-mail or telephone) to clarify inconsistent replies. Responses could have been 
biased towards greater HR needs if countries perceived this as an opportunity to request increased support; however, this did not seem to happen, since few countries reported staff shortages.

The performance assessment component of the questionnaire assumed NTP managers could assess the HR gap by comparing existing staff numbers (at different service levels) with the product of the additional SS+ cases by the time spent in diagnostic/treatment activities. Although all the tasks were listed in the questionnaire, the interpretation of what constituted achieving each task was left to NTP managers; this could have affected their estimation of the time required. We are currently developing a more detailed task analysis tool that includes the breakdown of each TB control activity into specific single tasks and a description of what constitutes each task; this will facilitate future studies. Furthermore, this method accounted only for new SS+ cases: in some countries, health facility staff will spend more time dealing with relapses, treatment failures or other TB patients: On the other hand, in some HBCs some tasks are performed by NGOs or the private sector and this was not discounted.

Constraints to HR development such as poor HR data quality, lack of a comprehensive national HR plan/strategy and little attention to continuing education programmes [18] were common to HBCs. This study evidences the huge gap in HR data (more apparent in large countries such as China and India) and the variability in quality and validity of available information. This is not an isolated problem of TB control programmes, given the dearth of published data on HRH in LMICs. Decentralization, ongoing in many HBCs, could have contributed to worsening HR information at central level. Developing HR planning and management capacity at district level and generating HR information systems should accompany decentralization processes [19-21] so that decentral- ization does not result in decentralized chaos [19]. A comprehensive HRH database facilitates HR surveillance and the management and planning of HR development in the health system [20].

The 2nd ad hoc committee on the TB epidemic recommended addressing the health-workforce crisis by collaboratively developing policies to reduce barriers to creating and filling posts in HBCs; increasing staff recruitment and retention by improving working conditions in the health sector; promoting task analysis and HR needs assessments, HR planning and training at country level; and working together with other stakeholders to develop strategies to further mobilize HR for TB control [22]. In general there is poor communication between HR planning units in the $\mathrm{MoH}$ and other technical programmes. A starting point for many HBCs will be a rigorous appraisal of their current HRH through in-depth assessments. Calculating programme-specific HR requirements, and informing the HR planners in the $\mathrm{MoH}$, are two steps that are not consistently performed, resulting in a health care workforce often unaware of its own capacities and limitations.

\section{Conclusion}

(See Table 4.) There is urgent need to assist HBCs developing HR information systems so that the up-to-date information required for appropriate planning, managing and supporting their health care workforce can be available. NTP managers in HBCs were generally aware of the need for appropriately trained staff at different service levels and, in some countries, the need to redistribute existing staff. Many HBCs require support in developing HR planning and management capabilities; however, more information is needed from countries to understand what factors most influence HR capacity so that country-specific plans can be developed.

\section{Table 4: Conclusions}

\footnotetext{
I. A paradigm shift in our approach to HR is needed. The HR impact of health initiatives must be conveyed in an explicit, open and unambiguous way so that governments, planners, and financial and technical partners will have a clearer understanding of the urgency of the $H R$ crisis and will have to take a stand on addressing it.

2. HR information systems in HBCs must be developed/strengthened. Without some reasonably accurate information on the numbers, location, qualifications and skills of staff it is impossible to administer, manage or plan the health workforce in any effective manner.

3. There is a dearth of information on HR for disease control programmes in LIMC. There is a need to develop HR assessment tools allowing for the different disciplines involved in HR issues and to conduct in-depth studies using validated methodology.

4. It is important to improve the communication link between technical programmes and HR planning at central level. There is a need to support some HBCs in developing HR management skills and in capacitating personnel in the area of HR management and planning.

5. Training is an important component of HRH development; there is a need to identify the minimum requirements of training at different service levels required to obtain a universal standard of care for TB patients and to better standardize training materials, methodologies and courses.

6. There must be a twin-track approach to addressing the HRH crisis. Current shortages must be addressed with short-term interventions in line with medium/long-term solutions developed within the context of poverty reduction strategies and national medium-term expenditure frameworks.
} 
Human resources constraints in TB will not be solved by NTPs in isolation; they are and will remain a subset of the general health workforce. The degree of integration of the HR for TB within the health workforce will vary from partial to total, depending on local conditions. The same holds true for the supply side: different health programmes compete for finite $H R$, posing a strain on local health systems. The health workforce crisis for TB control must be addressed within the broader HR context. Without creative solutions there will not be enough trained health professionals to implement the strategies proposed by the priority disease control programmes.

Finally, a paradigm shift in the way we approach HR issues is needed. Up until now, the HR implications of public health interventions have been tacitly understood; the impact of healthcare initiatives on the limited health workforce has always been implicit, unspoken and often underrated. There is now a need to clearly convey the HR impact of health initiatives in an open, unambiguous manner. By endeavouring to make the HR implications of each existing and new public health intervention explicit, we hope governments, planners, and financial and technical partners will have a clearer understanding of the urgency of the HR situation and will have to take a stand on addressing the health care workforce crisis.

\section{Conflict of interests}

The author(s) declare that they have no competing interests.

\section{Acknowledgements}

This study was supported by the Stop TB Department, World Health Organization. The authors wish to thank NTP managers and regional and country-based WHO and NTP staff at HBCs who kindly provided HR data. The authors are grateful to Tomas Allen for his contribution to the literature review and to Robert Scherpbier, Norbert Dreesch, Carmen Dolea and Gijs Elzinga for their comments and advice.

\section{References}

I. World Health Organization: The world health report 2000: reducing risks, promoting healthy life Geneva 2002.

2. Corbett EL, Watt CJ, Walker N, Maher D, Williams BG, Raviglione MC, Dye C: The growing burden of tuberculosis: global trends and interactions with the HIV epidemic. Archives of Internal Medicine 2003, 163:1009-1021.

3. World Health Organization: WHO report 2004 Global tuberculosis control: surveillance, planning, financing Geneva 2004.

4. World Health Organization: Anti-tuberculosis drug resistance in the world Report number 2: prevalence and trends Geneva 2000.

5. World Health Organization: Resolution WHA 44.8, Tuberculosis Control Programme. Forty-fourth World Health Assembly Resolutions and Decisions Geneva 1991.

6. World Health Organization: Resolution WHA 53.3, Stop Tuberculosis Initiative. Report by the Director General. Fifty-third World Health Assembly Resolutions and Decisions Geneva 2000.

7. Millennium Development Goals [http://www.development
[ goals.org/]

8. The Stop TB Partnership: [http://www.stoptb.org/]

9. The Global Fund to Fight AIDS, Tuberculosis and Malaria [http://www.theglobalfund.org/en/]
10. Marchal B, de Brounwere V: Global human resource crisis. Lancet 2004, 363:2191-2192.

II. Kaber K, Van Damme W: Scaling up access to antiretroviral treatment in southern Africa: who will do the job? Lancet 2004, 364: $103-107$

12. Huddart J: Human resources and sustainable capacity building for health and development Department for Democracy and Social Development, SIDA, Stockholm 23-24 January 2003 Stockholm: SIDA; 2003.

13. Buchan J: What difference does (good) HRM make? Human Resources for Health 2004, 2:6 [http://www.human-resourceshealth.com/content/2/1/6].

14. Hanson K, Ranson MK, Oliveira-Cruz V, Mills A: Expanding access to priority health interventions: a framework for understanding the constraints to scaling-up. Journal of International Development 2003, I5: I-I4.

15. Wyss K: An approach to classifying human resources constraints to attaining health-related Millennium Development Goals. Human Resources for Health 2004, 2: I I [http://www.humanresources-health.com/content/2/I/III].

16. Martineau T, Martínez J: Human resources in the health sector: guidelines for appraisal and strategic developments 1997 [http://www.liv.ac.uk/ Istm/hrdcover.html].

17. Kurowski C, Wyss K, Abdulla S, Yemadji ND, Mills A: Human resources for health: requirements and availability in the context of scalingup priority interventions in low-income countries Case studies from Tanzania and Chad HEFP working paper 0I/04 London: London School of Hygiene and Tropical Medicine; 2004.

18. Alwan A, Hornby P: The implications of health sector reform for health resources development. Bulletin of the World Health Organization 2002, 80:56-60.

19. Dovlo D: Health sector reform and deployment, training and motivation of human resources towards equity in health care: issues and concerns in Ghana. Human Resources for Health Development Journal 1998, 2(I): [http://www.moph.go.th/ops/hrdj/ Hrdj no3/table contents.html].

20. Kolehmainen-Aitken R: Decentralization and human resources: implications and impact. Human Resources for Health Development Journal 1998, 2(I): [http://www.moph.go.th/ops/hrdj/Hrdj no3/ table contents.html].

21. Rigoli F, Dussault G: The interface between health sector reform and human resources in health. Human Resources for Health 2003, I(9): [http://www.human-resources-health.com/con tent/I/I/9].

22. World Health Organization: Report on the meeting of the second ad hoc Committee on the TB epidemic Geneva 2004.

\footnotetext{
Publish with Biomed Central and every scientist can read your work free of charge

"BioMed Central will be the most significant development for disseminating the results of biomedical research in our lifetime. " Sir Paul Nurse, Cancer Research UK

Your research papers will be:

- available free of charge to the entire biomedical community

- peer reviewed and published immediately upon acceptance

- cited in PubMed and archived on PubMed Central

- yours - you keep the copyright

Submit your manuscript here:

http://www.biomedcentral.com/info/publishing_adv.asp

BiolMedcentral
} 